San Jose State University

SJSU ScholarWorks

Master's Theses

Master's Theses and Graduate Research

1989

\title{
Effects of HIV peer education on the knowledge, beliefs, and attitudes of high school seniors
}

William Webster Marshall

San Jose State University

Follow this and additional works at: https://scholarworks.sjsu.edu/etd_theses

\section{Recommended Citation}

Marshall, William Webster, "Effects of HIV peer education on the knowledge, beliefs, and attitudes of high school seniors" (1989). Master's Theses. 3094.

DOI: https://doi.org/10.31979/etd.n5dv-bcbf

https://scholarworks.sjsu.edu/etd_theses/3094

This Thesis is brought to you for free and open access by the Master's Theses and Graduate Research at SJSU ScholarWorks. It has been accepted for inclusion in Master's Theses by an authorized administrator of SJSU ScholarWorks. For more information, please contact scholarworks@sjsu.edu. 


\section{INFORMATION TO USERS}

The most advanced technology has been used to photograph and reproduce this manuscript from the microfilm master. UMI films the text directly from the original or copy submitted. Thus, some thesis and dissertation copies are in typewriter face, while others may be from any type of computer printer.

The quality of this reproduction is dependent upon the quality of the copy submitted. Broken or indistinct print, colored or poor quality illustrations and photographs, print bleedthrough, substandard margins, and improper alignment can adversely affect reproduction.

In the unlikely event that the author did not send UMI a complete manuscript and there are missing pages, these will be noted. Also, if unauthorized copyright material had to be removed, a note will indicate the deletion.

Oversize materials (e.g., maps, drawings, charts) are reproduced by sectioning the original, beginning at the upper left-hand corner and continuing from left to right in equal sections with small overlaps. Each original is also photographed in one exposure and is included in reduced form at the back of the book. These are also available as one exposure on a standard $35 \mathrm{~mm}$ slide or as a $17^{\prime \prime} \times 23^{\prime \prime}$ black and white photographic print for an additional charge.

Photographs included in the original manuscript have been reproduced xerographically in this copy. Higher quality $6^{\prime \prime} \times 9^{\prime \prime}$ black and white photographic prints are available for any photographs or illustrations appearing in this copy for an additional charge. Contact UMI directly to order.

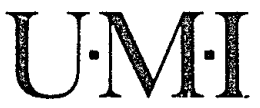



Order Number 1337828

Effects of HIV peer education on the knowledge, beliefs, and attitudes of high school seniors

\author{
Marshall, William Webster, M.S. \\ San Jose State University, 1989
}

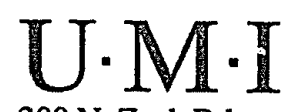



EFFECTS OF HIV PEER EDUCATION ON THE KNOWLEDGE, BELIEFS, AND ATTITUDES OF HIGH SCHOOL SENIORS

\author{
A Thesis \\ Presented to \\ The Faculty of the Department of Nursing \\ San Jose State University
}

In Partial Fulfillment

of the Requirements for the Degree

Master of Science

By

William Webster Marshall

May 1989 
APPROVED FOR THE DEPARTMENT OF NURSING

tharia farama

Virgil parsons, RN, DNSC

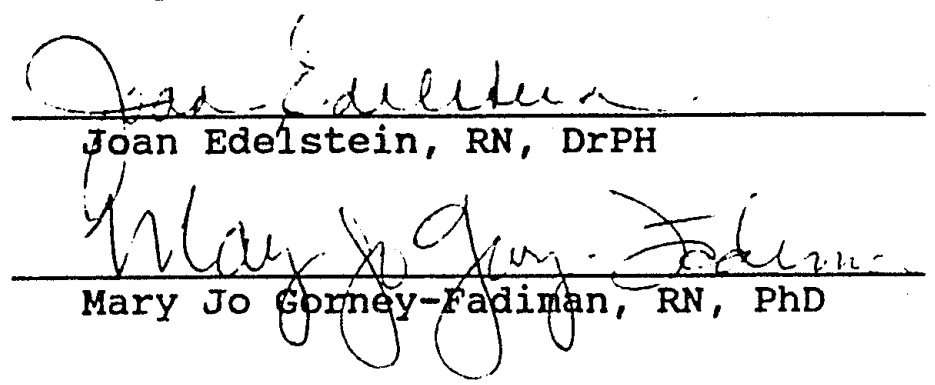

APPROVED FOR THE UNIVERSITY

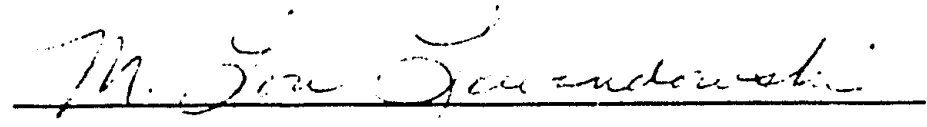




\section{ABSTRACT}

EFFECTS OF HIV PEER EDUCATION ON THE KNOWLEDGE, BELIEFS, AND ATTITUDES OF HIGH SCHOOL SENIORS

by William Webster Marshall

This thesis deals with the use of peer educators as a strategy for teaching high school students about HIV infection. The study was conducted in a central California high school, and the sample consisted of 69 high school seniors, who were fairly evenly divided between males and females and represented a mixture of ethnic backgrounds. The findings indicate that this group is fairly knowledgeable regarding $\mathrm{HIV}$ infection transmission and prevention. Also, the data show a positive attitude toward peer educators teaching about HIV infection and AIDS. The students requested more HIV information and AIDS education from peers and adult teachers. 


\begin{abstract}
ACKNOWLEDGEMENTS
To Mimi Fields, Chequita McCullough, JoAnn Kent, Anne Priebe, Jean Curtis, Phyllis Crockett, "Ad" Addleman, Dolores Nielson, the faculty and students of the San Jose State University graduate nursing program, the HIV high school peer educators who live the peer education concept daily, my typist, Debbi Ritchie; and last, but in no way least, my friend and lover, Betty Horn-Maraver.
\end{abstract}




\section{TABLE OF CONTENTS}

Page

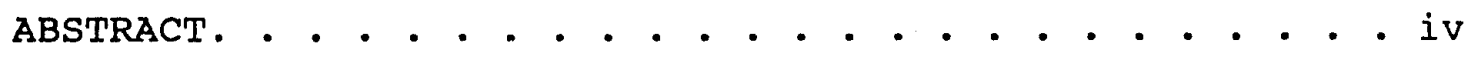
Chapter

1. INTRODUCTION. . . . . . . . . . . . . . . . . 1 Problem. . . . . . . . . . . . . . . 3 Purpose and Need . . . . . . . . . . . . 4 Definition of Terms. . . . . . . . . . . 5 Research Question. . . . . . . . . . . 5 setting and Sample Population. . . . . . . . 5 Research Design Overview . . . . . . . . . 6 Scope and Limitations. . . . . . . . . . . 7

2. CONCEPTUAL FRAMEWORK AND REVIEW OF THE LITERATURE. • . • . . . . . . . . . . 8 Conceptual Framework . . . . . . . . . . . . 8 Review of the Literature . . . . . . . . . . .11

3. RESEARCH DESIGN AND METHODOLOGY. . . . . . . . . 15

4. ANALYSIS AND INTERPRETATION OF DATA. • . . . . 18 Description of the Sample Population . . . . . . 18 Sex, Ethnicity and School Class Level. . . . . .18 Results of the Knowledge Assessment. . . . . . . 23 Results of Attitudes about HIV Infection Assessment . . . . . . . . . 26 
Results of Assessment of Attitudes

About HIV Education . . . . . . . . 30

4. ANALYSIS AND INTERPRETATION OF DATA

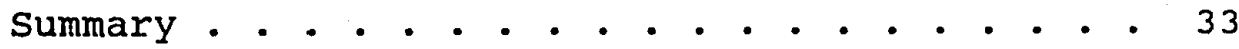

5. CONCLUSIONS AND RECOMMENDATIONS. . . . . . . 35

Summary . • . . . . . . . . • . . . . 35

Major Findings. . . . . . . . . . . . . 36

Limitations . . . . . . . . . . . . . 37

Inferences. . . . . . . . . . . . . . 39

Recommendations . . . . . . . . . . . 40

Concluding statement. . . . . . . . . . . . 41

REFERENCES . . . . . . . . . . . . . . . . . . .42

APPENDIXES . . . . . . . . . . . . . . . . . . .45

A. Consent Letter. . . . . . . . . . . 46

B. Sample Questionnaire. . . . . . . . . 47

C. Questionnaire Responses . . . . . . . . 51 


\section{LIST OF TABLES}

Table

1. Number and Percentage of Respondents

According to sex. . . . . . . . . . . 19

2. Numbers and Percentage of Female

Respondents According to Ethnicity. . . . 19

3. Numbers and Percentage of Male

Respondents According to Ethnicity. . . . 20

4. Numbers and Percentage of Female Respondents

According to Instruction Received . . . . . 22

5. Numbers and Percentage of Male Respondents

According to Instruction Received . . . . . 22 
Chapter 1

INTRODUCTION

Human Immunodeficiency Virus (HIV) infection is the fastest spreading viral infection in the United States today, according to surgeon General C. Everett Koop (1986). HIV is a blood-borne retrovirus that is passed from human to human. There is currently no cure for HIV infection, but much research is being undertaken in the private sector as well as public agericies to find a cure. Estimates for the discovery of a cure or vaccination against HIV infection vary from 3-10 years or longer, according to Koop. Many researchers feel that a total cure for those already infected with HIV is not a realistic hope. A vaccine may be forthcoming in the next few years, but this is speculation.

With the rate of infection with HIV incressing among select ethnic groups and youth, most public health officials feel that education is the only current tool available to slow the spread. In addition, statistics show that sexual activity increases dramatically during the teenage years. By age $15,16 \%$ of boys and $5 \%$ of girls in the U.S. have had heterosexual intercourse at least once. By age 17, these rates almost triple for boys and increase five times for girls. By age 19, three-quarters of all boys and almost two-thirds or all girls have been sexually active (Bennett, 1987, p. 5). Also, research has shown that most teenagers 
are not currently using condoms. Bennett (1987) reported on a 1986 survey showing that $53 \%$ of the sexually active teenage boys did not use condoms. One out of four persons with gonorrhea or syphilis was between the ages of 10 and 19 (Bennett, 1987).

The goal of education about the origin, transmission, and prevention of $\mathrm{HIV}$ infection is to produce a change in behavior. It is assumed that behavior changes by persons who are at increased risk for HIV infection (such as teenagers) will be effective in slowing the HIV infection rate. Education of youth is particularly important. Young people tend to feel invulnerable, and they experiment with lifestyles, sexuality, social groupings, drugs, and alcohol as a part of development (Diclemente, 1986). Although the number of cases of full-blown Acquired Immunodeficiency Syndrome (AIDS) in youth is low, one must not be misled by this statistic. Currently, AIDS, as defined by the centers for Disease Control (CDC) in Atlanta, Georgia, is the only category of HIV infection that is reportable. What this means is that at least two to as nany as five million people in the U.S. may already be infected with HIV and stili be asymptomatic. This estimate is based on CDC projections. There is no accurate way of telling how many of the currently infected persons are teenagers or preteens. It must be assumed that some teenagers are currently HIV infected. This assumption is based on an understanding of 
the sexual activity and drug activity of teens in the U.S. (Bennett, 1987).

The community health nurse (CHN) is challenged by the silent spread of HIV infection. Once infected with HIV, a person can feel and look healthy for many years, but most worldwide researchers now believe they will eventually develop symptoms of AIDS-Related Complex (ARC) or AIDS if given enough time. The cHN works within the community and the family to restore and maintain health and well being. As such, the CHN sees the spread of HIV to youth as a great threat and must locate or develop effective methods to educate youth on HIV transmission and prevention. In order to respond to the HIV epidemic, the CHN must search out innovative, yet effective, methods of ensuring that young people are educated.

\section{Problem}

With HIV apparently infecting an ever-increasing number of young people, the $\mathrm{CHN}$ is encouraged to bring the knowledge of various methods of education into the battle to control the spread of HIV infection. This study looked at the knowledge base and attitudes of high school seniors who were educated by same-age or near same-age peer educators in a high school in central California. The use of peer educators to teach about drug use and sexual choices has some history in high schools (Bennett, 1987). Because teenagers face a variety of problems today, using peer 
educators to help reduce those health risks seems to be warranted in light of the HIV epidemic.

Purpose and Need

HIV infection is pandemic. In the U.S. alone, the Surgeon General projects that by 1991, over 150,000 people will have been diagnosed with full-blown AIDS. It is estimated that at the current projected rate of $\mathrm{HIV}$ infection, 10 million or more persons in the U.S. will have already been infected with HIV yet are still asymptomatic by 1991 (Koop, 1986).

HIV infection has a great impact on the CHN. The CHN assesses the health status of the community and the family, and this assessment yields great needs for education about transmission of HIV and ways of preventing HIV infection. To accomplish this overwhelming task, the cHN must enlist the active support of those able to learn and teach the basics of HIV transmistion. In the case of teaching youth, the CHN may give the most aid to youth by training and supporting large numbers of young people as HIV peer educators. This method of training trainers is a costeffective use of the cHN's time. There are no studies documented in the litarature which report the use of high school peer educators to teach HIV transmission and prevention in the schools. The results of this study will begin to build a knowledge base in the area of HIV peer education. 
Definition of Terms

The following terms were defined for this study:

1. Reer education: The sharing of information, attitudes and behavior by people who are not professionally trained instructors and whose goal is to educate. Peer educators are defined as being within 3 years of age (older) of the students they are teaching. Peer education is seen as taking place constantly on an informal basis among most people.

2. Community Health Nurse (CHN): A registered nurse prepared through a baccalaureate program, employed by an agency to provide health promotion and education services to clients in a community setting.

\section{Research Question}

The research question asked was: will students in a high school HIV education class demonstrate a high level of knowledge about HIV transmission and prevention, and have positive attitudes about peer education when taught by trained peers? Answers to this question were sought by the use of an instrument developed by the investigator to gather information from the students (Appendix B).

Setting and Sample Population

The participants were students in a high school in central California. Characteristics such as sex, ethnicity, socioeconomic status, and previous knowledge about HIV were not controlled because of the nature of the class-by-class 
selection method. The participants were enrolled in high school and voluntarily willing to complete the instrument and return it to the school nurse.

In the capacity of a CHN and at the invitation of the high school principal, the investigator tabulated these data. The fact that the participants were volunteers may bias the results. Parental permission had been obtained by the school before the HIV class was taught by the peer educators. The administration of the instrument was seen by the school as the evaluation phase of the HIV peer education program. The investigator obtained the written permission of the school principal to assess and report the results of the survey for a Master's degree thesis (Appendix A). Research Design Overview

The design of the study was exploratory and descriptive. There was no randomization of participants, and there were no controls placed on the knowledge base and attitudes of the students entering the HIV education class for the first time. Peer educators taught each class using the same outline, flip chart, and videotape for their presentations. An instrument was administered after the class to measure the knowledge, beliefs, and attitudes of high school seniors regarding HIV and AIDS. No pretesting was possible due to constraints placed upon the investigator by the school. In addition, the instrument asked students about their thoughts regarding HIV peer education. 
Descriptive statistics were used to organize the results of the instrument. Inferences were made to analyze the results of the study.

\section{Scope and Limitations}

The study was based on certain assumptions. It was assumed by the investigator that students volunteering to participate in the post class evaluation would do so with a certain degree of seriousness and truthfulness. The time of day or class period was also not controlled by the investigator. In addition, it was assumed that the environment of the different classrooms at the high school was similar and provided similar levels of comfort.

The nature of the design was exploratory. The students in the study were volunteers from one high school in central California and may not be representative of students in other high schools even in the same area. The students completed the instrument after receiving the 55 minute HIV education class by two peer educators, backed up by an adult HIV educator. When completed, the students left and went to other classes. For scoring purposes, each item on the instrument was weighted equally.

Due to constraints by the high school, it was not possible to design a study to avoid these limitations. Therefore, the findings are likely to be suggestive of trends that warrant further investigation with larger sample sizes and varying ethnicity. 
Chapter 2

CONCEPTUAL FRAMEWORK AND REVIEW OF THE LITERATURE Conceptual Framework

The conceptual framework for this study was drawn from Orem (1971), whose principles of self-care and seli-care ability, as well as her view of health as a state of wholeness for functioning, laid the groundwork for the learning strategy used. Peer HIV educators, who use concepts similar to Orem's (1971), work with their own group to influence knowledge and choices of behaviors.

Individuals perform self-care behaviors designed to positively influence their self-care needs. For example, an adolescent performs certain behaviors that promote development and prevent illness or infection using information and advice from health care providers, family and friends (peers). Orem (1971) explains that if people cannot perform self-care because of changes in their health status, or insufficient or incomplete information, assistance in meeting self-care demands is needed from nurses. This need creates a valid nursing relationship when the community cannot or is not able to provide preventive information to adolescents. Nursing, in this case community health nursing, has a special domain in providing therapeutic self-care education and support to adolescents at risk for HIV infection. The overall goal of community 
health nursing, using Orem's (1971) model, is to return the individual to an enhanced self-care ability. Individuals must be knowledgeable, but more importantly must be able and willing to modify behavior towards safer sexual and drug choices.

Simply presenting facts, no matter who does it or how it is done, does not mean that learning will take place (Diclemente, 1986). Learning assumes an active learner, as well as an informed and trained teacher. When education about sex and drug choices is entered into, a degree of trust must be present for the learner to gain knowledge (Finn, 1981).

Orem's (1971) self-care theory fits with the goals of peer education. Teaching people of the same age by trained peer educators has been around for many years in the U.S. (Steinhausen, 1983). Peer HIV education is a new phenomenon that this investigator has found is gaining more acceptability among northern California HIV educators. The literature does not reilect any of this data as related to AIDS education and HIV transmission, but that is thought to be more the product of publishing lag time than lack of current efforts. The role of the $\mathrm{CHN}$ will be to enhance the self-care ability of youth. Enabling youth to educate each other, by empowering them with the facts, methods, and an environment within which to teach, gives orem's (1971) goal of optimal wellness through self-care and therapeutic 
self-care ability more chance to take hold.

Education, including teaching and learning, is a lifelong process. No one is always a teacher or always a learner. Both should occur simultaneously for the teacher and the student to grow. Finn (1981) reports that studies of peer education programs show that education done by peers is a powerful tool for change of behavior. He cites the success of peers in various health education programs, such as high blood pressure control, diet, and smoking cessation (Finn, 1981, p. 92).

In keeping with the CHN's role as an educator and facilitator of education, the selection of the HIV peer educators needs to follow a natural type of selection. For example, the use of "natural helpers" was explored by the investigator. As explained by Priebe anid Curtis (1987) in personal communications with the investigator, "natural helpers" in a school are those students to whom other students may turn if they have a problem. These "natural helpers," therefore, have a constituency of other students based upon some level of trust or other attraction. HIV peer educators at the high school level can be chosen from the supply of already existing "natural helpers" on campus. In conclusion, learning the facts about HIV transmission and prevention takes active and informed educators. It also takes active, trusting, and alert students who want to learn. The CHN who is aware that youth 
want and need correct information, upon which to base decisions about sex and drug behavior, realizes that the use of trained peers can assist in educating larger numbers of students. Orem's (1971) principles of self-care and the need for quality self-care among youth to educate and reeducate each other help justify the use of peer HIV educators in high school classrooms, and her writings laid the foundation for this investigator's HIV peer education effort and study.

Review of the Literature

The value of peer educators in teaching concepts, facts and attitudes to other peers is acknowledged by most health educators (Schunck \& Cox, 1387). Peers have been used for many years in health education classrooms to teach facts and concepts about drug use, healthy living, smoking cessation, and exercise (Finn, 1981). Peers have been and are currently being used as counselors in both high schools and colleges to teach health-related topics; such as stress reduction and contraceptive usage (White, 1987). However, no formal research on the use of peers as HIV educators in high schools and colleges was found in the literature. Traditionally, peer educators and counselors have been used to facilitate and supplement sexual education and drug education classes. Nagelberg (1981) evaluated a preventive peer health education program at Bowling Green University and found that peer health educators contributed 
substantially to the effectiveness of exercise promotion and smoking cessation efforts. Although there was no ability in this study to ascertain the long-term change in behavior, peer health educators were evaluated by students as a positive adjunct and were effective in educating fellow students.

Peers as tutors in school settings is not a new concept. Gerber and Kauffman (1981) report that peer tutors in schools date back to the early years of the nineteenth century. Children of various age strata were required to help educate younger children in schools where teachers were sparse. Using peers as tutors is a natural process that takes place constantly at all levels of schooling (Finn, 1981). Students at all ages seem to be constantly educating and influencing their peers by giving advice on matters such as school assignments, health and safety, and even highly technical inforration.

Peer education as a strategy to educate young people has a few precepts that should be considered (Finn, 1981). one is that the peer educator should be someone who is listened to by a certain group of fellow students. The peer educator should have the ability to choose and use a variety of education strategies when working with peers. Role modeling also appears to be an important aspect of successful peer education strategies. The ability to give factual and non-judgmental information, as well as knowing 
local reference sources, seems to be important.

The use of peer group pressure to change behavior is reported to be a very helpful motivator during adolescence (Greenwood \& Hops, 1981). The influence of an adolescent's family upon his or her behavior is more important and formative in the pre-teen years than during adolescence. Adolescents want and need social validation and acceptance for what they believe and do. Thus, peer educators and tutors can have an important impact upon adolescent knowledge and probably on behavior.

Steinhausen (1983) studied peer education programs across the U.S. and found that there were a variety of recruitment strategies and criteria for peer educators. Many schools recruited peer educators through the peers' stated interest in the particular program or curriculum beyond mere attainment of a grade. Other schools depended upon teacher recommendations to build a pool of peer educator-trainees: In a little over half of the cases, schools offered the peer educators credit for getting trained and teaching.

Phoenix (1987) found that involving students in the education process motivates them to learn more and teach others. Students in colleges tend to rate teachers higher who can actively reach out to students, encourage them to learn, and get other students involved in classroom settings as peer teachers. These educators tended to respond more to 
verbal communication than to just lecturing to students. Successful educators also iend to encourage more student-to-student talk, thereby reinforcing peers educating peers as a valid teaching-learning strategy.

White (1987) studied the influence of parents and peers upon the contraceptive use behavior of adolescent women. She found that when parents were supportive of their daughters using birth control, the rate of contraceptive use went up. Also, when peers of the same age or 2-3 years older approved of either early coitus or use of contraceptives, the adolescents were in a similar manner affected. Peers do affect the behavior of teenagers in regard to sexual choices and contraceptive use (White, 1987 )

Whether by role imitation or cognitive influence, the literature supports the concept of peers being able to influence peers. This influence may continue for a lifetime. If a structured program of selection, recruitment, training, and backup are applied to a peer HIV education program, the results can be a cost-effective and ongoing education process on school campuses. 
Chapter 3

RESEARCH DESIGN AND METHODOLOGY

The design of the study was exploratory and

descriptive. Randomization of participants was not possible due to constraints placed upon the investigator by the school. No controls were placed on the knowledge base and attitudes of the students entering the HIV education class.

HIV peer educator candidates were chosen by the school nurse using a selection process called "natural helpers." At the beginning of the school year, each student at the school voted anorymously on a slip of paper for two fellow students to whom they would turn if they had a serious problem. These ballots were submitted to the school nurse and tabulated. The students receiving the largest number of votes were contacted by the nurse and invited to participate in the HIV peer educator training. The process of identifying "natural helpers" on campus greatly aided the implementation of the HIV peer education program, and other peer counselor programs. The nurse reported that representatives from all peer groups were identified and offered the training.

Once selected, the "natural helpers" obtained the written permission of their parent or guardian to receive the peer educator training. The training was designed by the CHN with the assistance of the scinool nurse. Course 
content focused on the psychosocial aspects of HIV infection, the virus and its progression, the immune and central nervous systems, transmission, prevention, and local resources.

The time spent training the peer educator candidates was 12-14 hours. Sessions were conducted on campus, either after school or on weekends, as well as during the summer recess. Training sessions for the peer educator candidates were co-taught by the CHN, a local M.D., and two school. nurses. All candidates who attended the training sessions graduated. All the newly-trained peer educators co-taught HIV classes to their fellow students during the school year. A standard set of flip charts, course outline, and American Red Cross video was used by all peer educators for every classroom presentation. No pretesting was done prior to the HIV peer-taught classes at the request of the school. Unable to locate an appropriate instrument to measure knowledge, beliefs and attitudes about HIV infection and peer education, the investigator designed a questionnaire. To date, the instrument remains untested for its validity. The questionnaire (Appendix B) was composed of 41 questions. The first 27 questions and question \#30 were knowledge questions; the next two questions, and questions \#31-34, assessed attitudes regarding HIV infection; questions \#36-40 assessed attitudes regarding HIV education and peer education; and, the last question (\#41) assessed the sex, 
ethnicity, and class level of the sample. Each knowledge and attitude item was given the value of one point. The respondent had three choices per question: true, false, or I don't know. The last question was to determine the sex, ethnicity, and class level of the respondent.

once the school nurse had approved the instrument, she administered it to three senior classes who had already received instruction by trained peer educators during the school year. The instruments were completed by the students and returned to the nurse at the end of the class. The school nurse notified the investigator, requesting that he tabulate and analyze these data. The design of the questionnaire and its administration were done with the full knowledge and approval of the school administration.

The investigator obtained written permission from the school principal (Appendix $A$ ) to analyze and interpret these data and use the results in his thesis for a Master of Science in Nursing degree. The results have also been shared with the school nurse who has used them to modify and expand the peer education program. 


\section{Chapter 4}

\section{ANALYSIS AND INTERPRETATION OF DATA}

The findings and data analysis of a survey of central California high school seniors' knowledge and attitudes regarding HIV infection, prevention, and HIV educational efforts in the high school are described in this chapter. Demographic characteristics of the sample (respondents), the results of a general knowledge test, and the attitudes of the respondents regarding $\mathrm{HIV}$ infection and HIV high school. peer education are described.

Description of the Sample Population - Data collection questionnaires were given to students who had the opportunity to attend a peer taught HIV class during the school year. of the 78 data collection questionnaires distributed by the high school nurse to senior class members, 69 were returned. The school nurse informed the investigator that nine of the data collection questionnaires were not returned to her by the senior class students. The return rate was $88.5 \%$.

$$
\text { Sex, Ethnicity and School class Level }
$$

Tables 1-3 represent the numbers and percentages of the sample population (respondents) according to sex, ethnicity, and instruction in HIV. Regarding sex (Table 1), 36 of the respondents were female $(52.2 \%)$, and 33 of the respondents were male $(47.8 \%)$. None of the respondents reported their 
age. All of the respondents reported their class level to be high school senior. Approximately $75 \%$ of the respondents are dependents of military personnel stationed at a nearby military installation.

Table 1

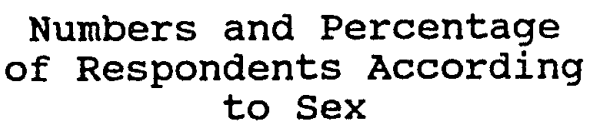

\begin{tabular}{|lcc|}
\hline Sex & $\underline{\mathbf{N}}$ & \% \\
\hline Female & 36 & 52.2 \\
Male & 33 & 47.8 \\
\hline Total & 69 & 100.00 \\
\hline
\end{tabular}

Table 2

Numbers and Percentage

of Female Respondents According

to Ethnicity

\begin{tabular}{|lcc|}
\hline Ethnicity & $\underline{N}$ & $\frac{8}{0}$ \\
\hline Hispanic & 9 & 25 \\
Asian & 4 & 11.1 \\
White & 12 & 33.3 \\
Black & 6 & 16.7 \\
Native American & 1 & 2.8 \\
Mixture of 2 or more & 4 & 11.1 \\
\hline Total & 36 & 100.00 \\
\hline
\end{tabular}


Table 3

Numbers and Percentage

of Male Respondents According

to Ethnicity

\begin{tabular}{|lcc|}
\hline Ethnicity & $\underline{\underline{N}}$ & $\%$ \\
\hline Hispanic & 3 & 9.1 \\
Asian & 6 & 18.2 \\
White & 9 & 27.3 \\
Black & 6 & 18.2 \\
Native American & 0 & 0 \\
Mixture of 2 or more & 9 & 27.2 \\
\hline Total & 33 & 100.00 \\
\hline
\end{tabular}


Table 2 represents the numbers and percentage of female respondents by ethnicity. Regarding the ethnicity of female respondents, 9 (25\%) were Hispanic, 4 (11.1\%) were Asian, 12 (33.3\%) were White, 6 (16.7\%) were Black, 1 (2.8\%) was Native American, and 4 listed themselves as a mixture of two or more ethnic groups (11.1\%). Table 3 represents the numbers and percentage for the ethnicity of the male respondents. Three ( $9.1 \%$ ) were Hispanic, 6 (18.2\%) were Asian, 9 (27.3\%) were White, 6 (18.2\%) were Black, and 9 listed themselves as a mixture of two or more ethnic groups (27.2\%). This ethnic mix approximates the ethnicity of the entire school and the city where the school is located.

Tables 4 and 5 represent the number of respondents by sex that had received instruction about HIV and AIDS during the past school year. Thirty-three (91.7\%) females and 30 (90.9\%) males answered in the affirmative to this question. Two males and one female answered that they did not know whether they had a class on HIV and AIDS. This probably means they do not remember whether they attended a class during the past school year. Of the females who responded that they had been taught a class, 4 (80\%) of the Hispanics, 4 (100\%) of the Asians, 8 (75\%) of the Whites, 7 (100\%) of the Blacks, 1 (100\%) of the Native Americans, and 4 (100\%) of the mixed ethnicity answered affirmatively. For the male respondents, 2 (67\%) of the Hispanics, 4 (83\%) of the Asians, 8 (89\%) of the Whites, 7 (100\%) of the Blacks, and 7 
Table 4

Numbers and Percentage

of Female Respondents

According to Instruction Received

\begin{tabular}{|lcc|}
\hline Instruction & $\underline{N}$ & $\%$ \\
\hline Received & 33 & 91.7 \\
Not received & 2 & 5.5 \\
Did not know & 1 & 2.8 \\
\hline Total & 36 & 100.00 \\
\hline
\end{tabular}

Table 5

Numbers and Percentage

of Male Respondents

According to Instruction Received

\begin{tabular}{|lcc|}
\hline Instruction & $\underline{\mathrm{N}}$ & $\%$ \\
\hline Received & 30 & 90.9 \\
Not received & 1 & 3.0 \\
Did not know & 2 & 6.1 \\
\hline Total & 33 & 100.00 \\
\hline
\end{tabular}


(78\%) of the mixed ethnicity persons responded true. Results of the Knowledge Assessment

The data collection instrument was a questionnaire composed of 41 total questions. The first 27 questions and question \#30 were knowledge questions; the next two questions, and questions \#31-34, assessed attitudes regarding HIV infection; questions \#36-40 assessed attitudes regarding HIV education and peer education; and, the last question (\#41) assessed the sex, ethnicity, and class level of the population. Each knowledge and attitude item was given the value of one point. The respondent had three choices per question: true, false, or I don't know. The last question was to determine the sex, ethnicity, and class level, and the choices were as follows: male, female; Black, White, Hispanic, Asian, Native American; Freshman, Sophomore, Junior, Senior. The total knowledge score was calculated by the number of questions answered correctly. Incomplete or unanswered questions were totalled and subtracted from the 28 possible points, the highest possible score on the knowledge portion of the questionnaire.

The range of knowledge scores was from 19 to 28 . For the 69 respondents, the total number of questions answered correctly was 1071 out of 1932 (89\%); 28 questions times 69 respondents equals 1932. The total number of incorrectly answered questions was $231(12 \%)$. No questions were answered correctly by everyone. Seven questions $(1,4,9$, 
$17,18,19,20$ ) were answered correctly by every female respondent. No questions were answered correctly by every male respondent, although six questions $(2,4,17,19,20$, 21) were answered correctly by 32 of the 33 respondents. The most incorrectly answered question was \#12. Ten $(30.3 \%)$ of the male respondents and seven (19.4\%) of the females responded incorrectly to the question: "The cause of AIDS is unknown." This is a false statement. The cause of AIDS is infection with the virus, HIV. When this is compared to question \#2: "AIDS is caused by a virus called HIV," 32 (97\%) of the males and 35 (97\%) of the females correctly answered this question. It is possible that the respondents may have been confused by question \#12, thinking it was asking about the origins (versus cause) of AIDS.

The second most incorrectly answered question was \#22. Seven $(19.4 \%)$ of the females and one $(3 \%)$ of the males incorrectly answered: "People with AIDS usually have lots of other diseases as a result of HIV infection." Four $(12.1 \%)$ of the males and three ( $8.3 \%$ ) of the females did not know the answer to this question. It is true that people with AIDS are more susceptible to infections and diseases than people with healthy immune systems. Respondents may have confused the word "disease" to mean something other than opportunistic infection commonly seen in HIV infected persons diagnosed with AIDS.

The third most often incorrectly answered question was 
\#16: "Most people who get HIV infection usually go on to develop AIDS given enough time." This is a true statement; yet four (12.1\%) of the males and four (11.1\%) of the females answered this question incorrectly. Five (15.2\%) males and three ( $8.3 \%$ ) females did not know the answer to this question. From all current projections based on studies of person infected with HIV within the past 10 years, most experts believe this to be a true statement. This response from high school seniors may reflect an unrealistic hope that HIV infection will not end in the terminal diagnosis of AIDS. It may also mean that the message about the progressive nature of HIV infection is not reaching adolescents in this age group.

The fourth most frequently missed question, \#27: "There is a vaccine you can get to prevent getting HIV infection," was answered true by three (9.1\%) of the males, and three ( $8.3 \%$ ) of the females. Alarmingly, 11 (33\%) of the male respondents and $\operatorname{six}(16.7 \%)$ of the female respondents did not know the answer to this well publicized statement. Many of the male and female respondents did not know that there was no vaccine against HIV infection, or thought that such a vaccine does exist. Fourteen (42.4\%) of the males and $\operatorname{six}(16.7 \%)$ of the females fell into the above category of knowledge. This may indicate, again, that the hope for a magic bullet or "shot" against HIV infection is blocking the prevention message about infection to high 
school students. It may also mean that there are a lot of confusing messages bombarding teenagers about vaccine or treatment trials in the media.

other questions in the questionnaire demonstrate similar confusion about a cure for HIV infection and AIDS. Question "24: "There is no cure for AIDS," was answered, "I don't know," by 10 (30.3\%) males and two (5.5\%) females. In addition, question \#26: "AIDS can be cured if treated early," found 11 (33.3\%) of the males and three (8.3\%) of the females answering, "I don't know." There again appears to be a large amount of confusion about a solution to the problem of HIV infection and AIDS among these high school seniors.

A percentage of $88 \%$ for correctly answered questions and $12 \%$ for incorrectly answered questions indicates that these high school seniors are fairly knowledgeable overall about HIV infection and AIDS. At the same time, they would greatly benefit from more classes on the cause of $\mathrm{HIV}$ infection, relative risk factors for infection, and clarification on treatments versus cures. Misinformation still exists in this age group, even though most respondents reported having attended a class on HIV infection and AIDS at their school.

Results of Attitude About HIV Infection Assessment Questions \#28, 29, and 31-34 were designed to assess attitudes of respondents about HIV infection and AIDS. The 
fear of HIV infection and AIDS were also assessed by the above questions. Of the six questions, the one with the strongest response was question \#28: "HIV infection is not as big a problem as the media suggests." Twenty-one (63.6\%) of the male respondents and 34 (94.4\%) of the female respondents felt that this was a false statement. This indicates that these high school seniors feel that it is at least as big a problem as the media suggests, maybe larger. $\operatorname{six}(18.2 \%)$ of the males and one (2.8\%) of the females did not know the answer or have an opinion on this question. This may indicate that they are ambivalent about the statement that HIV infection is a serious problem.

There were two questions that assessed the level of fear of HIV infection of these respondents: questions \#29 and 31. Twenty-three (69.7\%) of the males and 29 ( $80.6 \%$ ) of the females answered true to question \#29: "I am afraid of getting HIV infection." Additionally, 22 (66.7\%) of the males and $28(77.8 \%)$ of the females answered false to question \#31: "I am not worried about getting HIV infection." The respondents answering, "I don't know," were relatively low compared to many of the above knowledge questions. Only six (18.2\%) of the males and one (2.8\%) of the females had no opinion either way on question \#31. This may indicate that these respondents are fearful of HIV infection, even though they are fairly knowledgeable about transmission and prevention of HIV infection. 
Questions \#32 and 33 were placed into this instrument to assess whether the respondents felt they were personally at risk for HIV infection. "I am not the kind of person who is likely to get HIV infection," question \#32, was answered true by $16(48.5 \%)$ of the males and 23 (63.9\%) of the females. Question \#33, "I am less likely than most people to get HIV infection," was, likewise, answered true by 18 (54.5\%) of the male respondents and 21 (58.3\%) of the female respondents. Nine (27.3\%) of the males answered questions \#32 and 33, "I don't know." Five (13.9\%) of the females answered question \#32, "I don't know." Question \#33 was answered, "I don't know," by $\operatorname{six}(16.7 \%)$ of the females. It appears that greater than $50 \%$ of the respondents do not feel they are the kind of people who will get infected with HIV. Less than $20 \%$ of the males and females responding seem to be unsure of their likelihood of HIV infection. This may indicate that they have some anxiety over it, but may not feel especially vulnerable at the present time. We do not know if these students are currently sexually active, or have not yet had sexual intercourse and plan to some time in the future. Nine (27.3\%) of the males and seven (19.4\%) of the females answered that they worried about getting HIV infection in question \#31.

Sixteen (23.2\%) of the total number of respondents to question \#32 felt that they were "...the kind of person who is likely to get HIV infection." Eight (24.2\%) were male 
and eight $(22.2 \%)$ were female respondents. To question \#33: "I am less likely than most people to get HIV infection," 15 respondents answered false. Fifteen additional respondents answered, "I don't know," to this question. Therefore, 30 (43.5\%) of the 69 respondents felt they were at risk, or were not sure. This may indicate that among this population, there is fear that HIV is "somewhere out there," indicating concern that they may get infected.

Most (44) of the respondents answered true to the statement in question \#34: "I'd rather get any other disease than AIDS." The female respondents felt stronger about this statement than the males, with $26(72.2 \%)$ of the females and only 18 (54.4\%) of the males responding in the affirmative. Ten (30.3\%) of the males did not know if they would rather have any other disease than AIDS. The investigator did not ask questions about other diseases that the respondents may have felt were as bad as AIDS, so it is not possible to assess why a larger percentage of the respondents did not answer that they would rather have diseases other than AIDS.

Question \#35: "If a free blood test was available to see if you have HIV, would you take it?" was answered true by $48(69.6 \%)$ of the respondents. Thirty $(83.3 \%)$ of the females wanted to take the test, and only 18 (54.5\%) of the males wanted to do likewise. This tends to follow the earlier response of males to other attitudinal questions. 
Males did not respond with the same degree of fear of HIV infection as their female counterparts. Males felt, or admitted less frequently, their vulnerability to HIV infection. Females admitted that they felt vulnerable to HIV infection and were afraid. Females responding thusly may indicate that they understand that they are the partner more at risk as the receptive partner than their male counterparts who are the insertive partners in heterosexual intercourse. Or, perhaps, this has to do with society's acceptability of the vulnerability of females as opposed to males.

To summarize, respondents believe that HIV infection is a big problem. Overall, they do not feel that media is exaggerating the seriousness of the epidemic. Both males and females still harbor fear of HIV infection, with females indicating they feel more at risk than males. Although the male respondents did not register the same high level of fear and vulnerability that the females did, they appear to be very unsure of their risk. Overall, the group fears HIV infection and would choose to take an HIV antibody test offered in the community.

Results of Assessment of Attitudes About HIV Education Sixty-three ( $91.3 \%)$ of the 69 respondents answered true to question \#38: "Have you had any instruction about HIV and AIDS in your school curriculum?" Three (4.35\%) responded that they did not have any instruction about HIV 
and AIDS, and three ( $4.35 \%$ ) responded that they did not know. The format at this school for the delivery of HIV and AIDS instruction was a 55 minute class delivered once per school year to each student. The investigator did not ascertain whether the respondents who answered in the negative missed the class of their own desire or were absent for other reasons, such as sickness or conflicting class activities. Parents of students were given the opportunity to remove their children from the 55 minute presentation. Most parents of the high school seniors allowed their sons and daughters to attend one of the classes during the year. This may have been an additional explanation. It is disturbing that nearly $10 \%$ of the respondents stated that they had not received, or could not recall receiving, instruction in the past year.

Most of the respondents answered that it was important to learn about HIV infection (question \#37). Sixty-four (92.8\%) of the 69 respondents responded positively to this statement. Five $(7.3 \%)$ respondents did not know; yet none of the 69 students responding felt HIV education should be left out of the curriculum. Sincerely, respondents want to know more about HIV and AIDS. Question \#36: "I've heard enough about AIDS and HIV and I don't want to hear anymore about it," was answered false by 51 (73.9\%) of the respondents. Twenty-nine $(80.6 \%)$ of the female respondents and 22 (66.7\%) of the males responded false to this 
statement. Five (15.2\%) of the males and $\operatorname{six}(16.7 \%)$ of the females felt that question \#36 was a true statement for them. They do not want to hear anymore about HIV infection and AIDS. Six (18.2\%) of the males and one (2.8\%) of the females answered, "I don't know," to this question. This may indicate that they are tired of hearing about the topic or the manner of its presentation, but feel that it is important enough an issue that they would attend more instructions in the future. Alternatively, this may be a reflection of their fears and a wish to protect themselves from adding to those fears.

Questions \#39 and 40 were designed to assess the attitude of respondents towards HIV high school peer education. Question \#39: "HIV peer educators at my school do a good job of educating about HIV and AIDS," was answered true by $52(75.4 \%)$ of the respondents. Thirty (83.3\%) of the females and $22(66.7 \%)$ of the males felt that peer educators did a good job in their school. Eight (11.6\%) of the respondents answered false to question \#39, and nine (13\%) answered, "I don't know." Question \#40 asked if students preferred only older adults like teachers, parents, or school nurses to teach them about HIV and AIDS. Nine (18.8\%) of the 69 respondents answered true to this statement. Forty-seven (68.1\%) of the respondents answered false to having only older adults educating them about HIV and AIDS. Nine (13\%) respondents (all of whom were male) 
answered, "I don't know," to this question. The female respondents showed no such ambivalence on this question. None of them answered, "I don't know."

To summarize, these data suggest that most of the responding seniors received at least one 55 minute class taught by peer educators, and that they do not have negative attitudes towards the effectiveness of their own peers educating them about HIV infection and AIDS in the classroom. Indeed, HIV peer educators at this school were looked upon favorably by these respondents. These data do not suggest an overwhelmingly negative attitude towards older adult educators teaching HIV classes. Some male respondents seem to possess no strong opinions about HIV peer education. Their female counterparts, though, seem to feel very positive about the HIV peer educators on campus. Summary

This study was conducted in a central California high school. The sample consisted of 69 high school seniors enrolled in the school.

The findings indicate that this sample tends to be fairly evenly divided between males and females. They are all members of the senior class and represent a mixture of ethnic backgrounds. Findings indicate that these high school seniors are fairly knowledgeable regarding HIV infection, transmission, and prevention. These data show a positive attitude towards peer educators teaching about HIV 
infection and AIDS in the classrooms. Findings also indicate a desire on the part of these students for more HIV and AIDS education and a fear among male and female respondents of vulnerability to HIV infection. Findings also indicate that male respondents answer, "I don't know," more frequently than their female counterparts on knowledge and attitude questions. Findings give no indication as to behaviors that these respondents engage in that may put them at risk for HIV infection. A survey of high risk sexual and drug behaviors correlated with attitudinal questions about HIV infection would be needed to further assess the relative risk-to-fear ratio of these high school respondents. 
Chapter 5

CONCLUSIONS AND RECOMMENDATIONS

This chapter contains the conclusions of this exploratory survey of high school seniors. Knowledge and attitudes regarding HIV infection and HIV educational strategies will be discussed. Inferences are made and recommendations are offered for future study.

Summary

This design was exploratory in nature, and survey methods were used. The target population consisted of 69 high school seniors. The respondents were fairly evenly split between females $(N=36)$ and males $(N=33)$.

The data collection instrument consisted of: (a) a demographic assessment, (b) a knowledge assessment composed of 28 questions, and (c) an attitude assessment composed of six questions on HIV infection and five questions on HIV education. The knowledge and attitude questions could be answered true, false, or I don't know.

The investigator assisted the target high school in developing the instrument since a validated HIV peer education instrument could not be located. The administration of the instrument and the collection of the completed questionnaires were done by the school nurse. The instrument was distributed by the nurse to 78 students. The nurse requested that the students fill out the questionnaire and return it at the end of the class period. The students 
were given as much time as they needed to complete the questionnaire. Participation by the students was voluntary, and anonymity was assured.

of the 78 questionnaires distributed by the school nurse, 69 were returned to the school nursing office, indicating a return rate of $88.5 \%$. The investigator obtained written permission from the school principal to tabulate these data and use them in this study. The investigator assured the principal that anonymity of the high school and the students would be maintained.

\section{Major Findings}

Information was gathered in this study regarding the knowledge and attitudes of high school seniors towards HIV infection, prevention, and HIV school education strategies. The findings from the instrument administered to the sample group indicate a fairly high level of knowledge about HIV infection and AIDS. The findings also indicate that the sample population possesses a fairly high degree of fear of HIV infection and feelings of vulnerability among responding students.

The top four most frequently missed questions in the knowledge questionnaire portion of the instrument specifically involved information dealing with infection with the virus and the availability of a cure or vaccination for infection. Misinformation exists for this group of high school seniors even after having attended a 55 minute class 
on HIV infection where this information was covered, albeit in limited detail. The responses to the questions about attitudes towards HIV infection and towards HIV education indicate that this sample of high school seniors feel vulnerable and fearful of HIV infection, yet desire their own peers to continue doing education with them as opposed to only older adults doing classes.

\section{Limitations}

Limitations to generalization are due to the size of the sample (69) and the location of the high school (central California). It is not to be implied that the findings obtained from this study are applicable to various populations of high school seniors throughout the United States. Generalization may be suggested to other high schools in central california with a similar ethnicity and class level.

Randomization would have reduced the population of respondents; therefore, random selection was not realistic. In addition, since the school nurse administered the questionnaire and collected it, and this investigator merely tabulated these data, randomization was not an option for this study.

Although an untested instrument was used, the respondents seemed able to answer questions in the knowledge, attitude, and demographic portion. The information requested was easily obtained, according to the 
school nurse who administered the questionnaire.

The use of 41 questions, including the demographic data question, was used for several reasons. First, it seemed to cover the subject of HIV infection and HIV education strategies fairly adequately. Secondly, it seemed to be less tiring for the respondents, according to the school nurse, than using a longer questionnaire. Thirdly, it made scoring and tabulating the data easier and quite uniform. clarification on individual questions could have been improved with revised wording or qualifiers. For example, 17 of the respondents (24.6\%) incorrectly answered question \#12. An additional 12 respondents (17.4\%) answered, "I don't know," to a statement that the cause of AIDS is unknown. Yet, for the above questions, 67 (97.1\%) answered that the cause of AIDS is a virus called HIV. Perhaps clarifying that the investigator was looking for the virus or germ that causes AIDS instead of the possible interpretation about the origin of the disease would have made the question more clear to the respondents. As a result, the question may have been incorrectly understood and answered.

Overall, $88.5 \%$ of the respondents completed and returned the data collection instrument to the school nurse within the requested period. It is not possible to assess whether the respondents felt hurried to complete the questionnaire and if this affected any of their responses. 


\section{Inferences}

The findings delineated from the knowledge and attitude assessments suggest that this sample group of high school seniors in central California possess a good overall knowledge regarding H.IV infection, prevention, and transmission of the virus. The female respondents scored higher on the knowledge portion than the male respondents. Respondents indicated no negative attitudes toward the HIV peer educators teaching for the past school year in their classes. They also indicated a very positive attitude toward future HIV and AIDS education, yet both males and females registered that they are fearful of becoming infected with HIV and feel vulnerable.

An inference can be made about the attitude of high school seniors regarding peer education as presented in Chapter 2 (Conceptual Framework and Review of the Literature). If negative attitudes in the culture exist toward the use of high school peer educators teaching about sex, drugs, and infectious diseases, then high school seniors, as members of society, should demonstrate these attitudes. Findings from this study indicate, though, that high school seniors have very positive attitudes toward peer sex and drug education, and possess a fairly high level of knowledge about the difficult and highly charged topic of HIV infection.

Another inference to be considered is that even though 
most of these seniors had attended a class on HIV infection, they still had high levels of anxiety and feared infection with HIV. The media, confusing messages from other peers and adults, and other considerations were involved with attitudes toward HIV infection. Predicting student behavior cannot be done by evaluating their knowledge and attitudes alone. There are no guarantees that the high scores on the knowledge portion of the questionnaire will positively influence students' sexual and drug use behavior.

\section{Recommendations}

The following recommendations are made based on the findings of this study:

1. Although the percentage of correctly answered questions was fairly high, the need for further classes on HIV infection and transmission is recommended.

2. More small group work with high school students is needed to help them explore their high fear of HIV infection and express their anxiety over infection. Attitudes will not necessarily change by simply presenting classes on HIV and AIDS. Students should be aided, through small group sessions, in expressing and exploring their inner feelings and fears of HIV infection.

3. Expanding the sample population to include settings in more urban and rural areas, and among varying ethnic groups, is needed. This would help to validate the effectiveness of peer education in a variety of settings. 
Concluding statement

The threat of HIV infection among adolescents is a major public health challenge. High school students experience feelings of invulnerability and engage in experimentation within the world. Such experimentation aids young people in developing their own sexual and social identity and being separate from their parents. Experimentation without a firm knowledge base of HIV infection and prevention can lead to risk behaviors. Behaviors not grounded in factual information can lead to infection with HIV and development of AIDS.

In order to live safely in the era of HIV infection, adolescents must be aware of their knowledge and attitude toward HIV infection. A good strategy in preventing HIV infection among adolescents is the use of highly trained representatives from various peer groupings at school as HIV peer educators and counselors. The development of a trusting relationship with a peer who knows the facts about HIV infection, and can teach the facts in formal and informal settings, is a worthwhile goal. 
REFERENCES 
References

Bennett, W. (1987). AIDS and the education of our children: A guide for parents and teachers. U.S. Dept. of Education.

Diclemente, R. (1986). Adolescents and AIDS: A survey of knowledge, attitude and beliefs about AIDS in San Francisco. American Journal of Public Health, 76(12), 1443-1445.

Finn, P. (1981). Institutionalizing peer education in the health education classroom. Journal of School Health, 25 (2), 91-95.

Finn, P. (1981). Teaching students to be lifelong peer educators. Health Education, 12(5), 13-16.

Gerber, M. \& Kauffman, J. (1981). Peer tutoring settings. In P. Strain (Ed.), Utilization of Classroom Peers as Behavior Change Agents, (pp. 155-187). New York. Greenwood, C. \& Hops, H. (1981). Group-oriented contingencies and peer behavior change. In $P$. Strain (Ed.), Utilization of Classroom Peers as Behavior Change Agents, (pp. 189-259). New York. Koop, C. E. (1986). Surgeon general's report on Acquired Immune Deficiency syndrome. U.S. Dept. of Health and Human Services, U.S. Public Health Service. 
Nagelberg, D. (1981). Evaluating a health risk reduction program. Journal of the American College Health Association, $\underline{29}(6), 2-6$.

Orem, D. (1971). Nursing concepts of practice. New York: McGraw-Hill.

Phoenix, c. (1987). Get them involved! styles of high and low-rated teachers. College Teaching, 35(1), 13-15. Schunck, D. \& Cox, P. (1987). Peer model attributes and children's achievement behaviors. Journal of Educational Psychology, 79(1), 54-61. Steinhausen, G. (1983). Peer education programs: A look nationally. Health Education, 14(7), 7-10.

White, J. (1987). Influence of parents, peers, and problem-solving on contraceptive use. Pediatric Nursing, $13(5), 317-321$. 
APPENDIX A

Consent Letter 


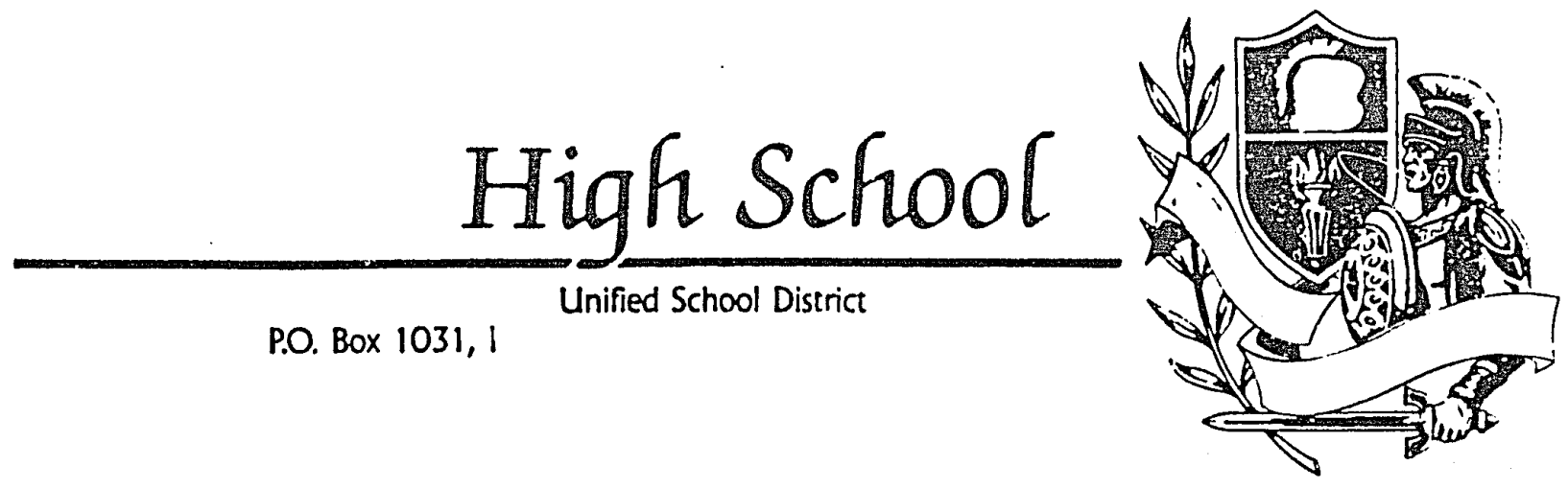

liay 10,1988

To Whom it May Concern:

I give permission for Mr. William W. Marshall, Fis to tabulate and use data from an instrument completed by seniors at High School. I give this permission for luse as part of Mr. Marshalls Master Thesis with the understanding that High will not be mentioned in the body of his thesis.

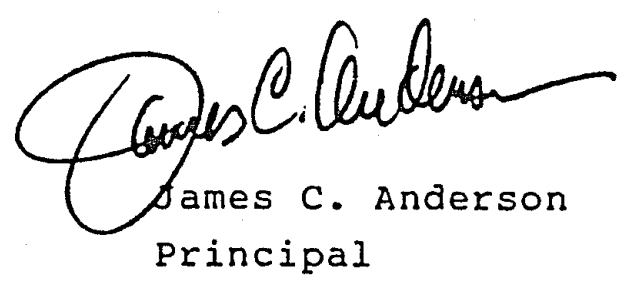


APPENDIX B

Sample Questionnaire 
Sample Questionnaire

Please answer each question honestly by circling the bes: response.

$$
\text { STATEMENT }
$$

1. AIDS is a medical condition in which your body cannot fight off disease.

2. AIDS is caused by a virus called HIV.

3. If you kiss someone with HIV infection you will get the disease (AIDS).

4. If you touch someone with HIV you will get infected.

5. All gay men have HIV infection.

6. The food you eat can give you HIV infection.

7. Anybody can get infected by HIV.

8. AIDS can be cured.

9. HIV can be spread by using someone's personal belongings like a comb or hairbrush.

10. AIDS is not at all serious, it is like having a cold.

11. AIDS is caused by the same virus that causes gonorrhea.

12. The cause of AIDS is unknown.

13. Just being around someone with HIV infection can give you the disease.

14. Having sex with someone who has HIV infection.

TRUE FALSE $\underset{\text { KNOW }}{\text { DON'T }}$

KNOW 
15. If a pregnant woman has HIV, there is a chance it may harm her unborn baby.

16. Most people who get HIV infection usually go on to develop AIDS given enough time.

17. Using a condom during sex can lower the risk of getting infected with HIV.

18. You can get HIV by shaking hands with someone who has it.

19. Receiving a blood transfusion with infected blood can give a person HIV infection.

20. You can get HIV infection by sharing a needle with a drug user who has the virus.

21. AIDS is a life-threatening disease.

22. People with AIDS usually have lots of other diseases as a result of HIV infection.

23. All gay women have HIV infection.

24. There is no cure for AIDS.

25. I can avoid getting HIV infection by exercising regularly.

26. AIDS can be cured if treated early.

27. There is a vaccination you can get to prevent getiting HIV infection.

23. HIV infection is not as big a problem as the media suggests. 
29. I am afraid of getting HIV infection.

30. Just living in the Monterey County increases my chances of getting HIV infection, regardless of what $I$ do.

31. I am not worried about getting HIV infection.

32. I am not the kind of person who is likely to get HIV infection.

33. I am less likely than most people to get HIV infection.

34. I'd rather get any other disease than AIDS.

35. If a free blood test was available to see if I have HIV, I would take it.

36. I've heard enough about AIDS and HIV and don't want to hear any more about it.

37. It is important that students learn about HIV and AIDS in Family Life Education classes.

38. I have had instruction about HIV and AIDS in my school curriculum.

39. HIV peer educators at my school do a good job of educating about HIV and AIDS.

40. I would prefer to have only older adults, like teachers, parents, or the school nurse, teach me about HIV and AIDS. 
41. Circle if appropriate to identify who you are.

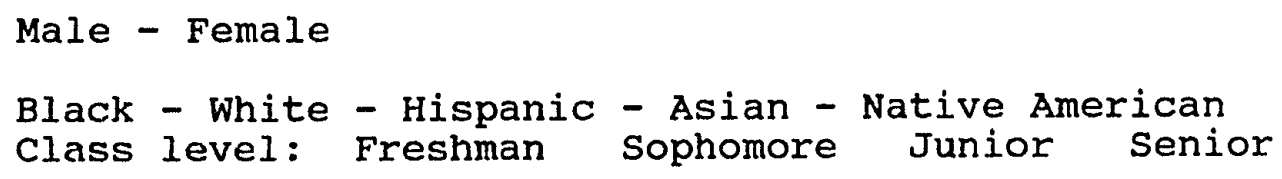


APPENDIX C

Questionnaire Responses 
Responses by Sex for Questions on Questionnaire

Please answer each question honestly by circling the best response.

STATEMENT

$\begin{array}{ll}\text { TRUE FALSE } & \text { DON'T } \\ \text { KNOW }\end{array}$

1. AIDS is a medical condition in which your body cannot fight off disease.

$\begin{array}{llllll}31 & 36 & 1 & 0 & 1 & 0\end{array}$

2. AIDS is caused by a virus called HIV.

$\begin{array}{llllll}32 & 35 & 1 & 1 & 0 & 0\end{array}$

3. If you kiss someone with HIV infection you will get the disease (AIDS).

$\begin{array}{llllll}0 & 1 & 29 & 34 & 4 & 1\end{array}$

4. If you touch someone with HIV you will get infected.

$\begin{array}{llllll}0 & 0 & 32 & 36 & 1 & 0\end{array}$

5. All gay men have HIV infection.

$\begin{array}{llllll}2 & 0 & 29 & 35 & 2 & 1\end{array}$

6. The food you eat can give you HIV infection.

$\begin{array}{llllll}1 & 2 & 27 & 33 & 5 & 3\end{array}$

7. Anybody can get infected by HIV.

$\begin{array}{llllll}29 & 35 & 3 & 1 & 1 & 1\end{array}$

8. AIDS can be cured.

$\begin{array}{llllll}0 & 0 & 29 & 32 & 4 & 4\end{array}$

9. HIV can be spread by using someone's personal belongings like a comb or hairbrush. $\begin{array}{llllll}0 & 0 & 29 & 36 & 4 & 0\end{array}$

10. AIDS is not at all serious, it is like having a cold.

$\begin{array}{llllll}2 & 0 & 31 & 35 & 0 & 1\end{array}$

11. AIDS is caused by the same $\begin{array}{lllllll}\text { virus that causes gonorrhea. } & 2 & 1 & 21 & 29 & 10 & 6\end{array}$

12. The cause of AIDS is unknown. $\begin{array}{lllllll}10 & 7 & 16 & 24 & 7 & 5\end{array}$

13. Just being around someone with HIV infection can give you the disease. 
14. Having sex with someone who

\begin{tabular}{cccccc}
\hline$M$ & $F$ & $M$ & $F$ & $M$ & $F$ \\
30 & 35 & 2 & 0 & 1 & 1
\end{tabular}

15. If a pregnant woman has HIV, there is a chance it may harm her unborn baby.

$\begin{array}{llllll}31 & 35 & 0 & 0 & 2 & 1\end{array}$

16. Most people who get HIV infection usually go on to develop AIDS given enough time.

$\begin{array}{llllll}24 & 29 & 4 & 4 & 5 & 3\end{array}$

17. Using a condom during sex can lower the risk of getting infected with HIV.

$\begin{array}{llllll}32 & 36 & 1 & 0 & 0 & 0\end{array}$

18. You can get HIV by shaking hands with someone who has it. $\begin{array}{lllllll}0 & 0 & 30 & 36 & 3 & 0\end{array}$

19. Receiving a blood transfusion with infected blood can give a person HIV infection.

$\begin{array}{llllll}32 & 36 & 0 & 0 & 1 & 0\end{array}$

20. You can get HIV infection by sharing a needle with a drug user who has the virus.

$\begin{array}{llllll}32 & 36 & 1 & 0 & 0 & 0\end{array}$

21. AIDS is a life-threatening disease.

$\begin{array}{llllll}32 & 35 & 0 & 0 & 1 & 1\end{array}$

22. People with AIDS usually have lots of other diseases as a result of HIV infection.

$\begin{array}{llllll}28 & 26 & 1 & 7 & 4 & 3\end{array}$

23. All gay women have HIV infection.

$\begin{array}{rrrrrr}1 & 0 & 28 & 34 & 3 & 2 \\ 23 & 34 & 0 & 0 & 10 & 2\end{array}$

25. I can avoid getting HIV infection by exercising regularly.

$\begin{array}{llllll}3 & 1 & 24 & 35 & 6 & 0\end{array}$

26. AIDS can be cured if treated early.

$\begin{array}{llllll}2 & 0 & 20 & 33 & 11 & 3\end{array}$


27. There is a vaccination you can get to prevent getting HIV infection.

$\begin{array}{llllll}3 & 3 & 19 & 27 & 11 & 6\end{array}$

28. HIV infection is not as big a problem as the media suggests. $\begin{array}{lllllll}6 & 1 & 21 & 34 & 6 & 1\end{array}$

29. I am afraid of getting HIV infection.

$\begin{array}{llllll}23 & 29 & 7 & 6 & 3 & 1\end{array}$

30. Just living in the Monterey County increases my chances of getting HIV infection, regardless of what I do.

$\begin{array}{llllll}0 & 4 & 21 & 30 & 12 & 2\end{array}$

31. I am not worried about getting HIV infection.

$\begin{array}{llllll}9 & 7 & 22 & 28 & 2 & 1\end{array}$

32. I am not the kind of person who is likely to get HIV infection. $\begin{array}{llllll}16 & 23 & 8 & 8 & 9 & 5\end{array}$

33. I am less likely than most people to get HIV infection. $\begin{array}{lllllll}18 & 21 & 6 & 9 & 9 & 6\end{array}$

34. I'd rather get any other disease than AIDS.

$\begin{array}{llllll}18 & 26 & 5 & 4 & 10 & 6\end{array}$

35. If a free blood test was available to see if $I$ have HIV, I would take it.

$\begin{array}{llllll}18 & 30 & 7 & 4 & 8 & 2\end{array}$

36. I've heard enough about AIDS and HIV and don't want to hear any more about it.

$\begin{array}{llllll}5 & 6 & 22 & 29 & 6 & 1\end{array}$

37. It is important that students learn about HIV and AIDS in Family Life Education classes. $\begin{array}{lllllll}30 & 34 & 0 & 0 & 3 & 2\end{array}$

38. I have had instruction about HIV and AIDS in my school curriculum.

$\begin{array}{llllll}28 & 32 & 3 & 3 & 2 & 1\end{array}$

39. HIV peer educators at my school do a good job of educating about HIV and AIDS. $\begin{array}{lllllll}22 & 30 & 6 & 2 & 5 & 4\end{array}$ 
$\begin{array}{ll}\text { TRUE FALSE } & \text { DON'T } \\ \text { KNOW }\end{array}$

$\begin{array}{llllll}M & F & M & F & M & F\end{array}$

40. I wolld prefer to have only older adults, like teachers, parents, or the school nurse, teach me about HIV and AIDS.

$\begin{array}{llllll}5 & 8 & 19 & 28 & 9 & 0\end{array}$

